\title{
SPREADSHEET AND ITERATION DEAD TIMES OF 2- ALKANONES HOMOLOGUES SERIES ELUTED BY ACETONITRILE/WATER IN REVERSED PHASE HIGH- PERFORMANCE LIQUID CHROMATOGRAPHY
}

\author{
R. Idroes ${ }^{1,2, \bowtie}$, M. Mahmudi ${ }^{1}$, S. Saiful ${ }^{1}$, M. Muslem ${ }^{3}$, G.M. Idroes ${ }^{4}$, \\ A. Rusyana ${ }^{5}$, R. Suhendra ${ }^{6}$ and I. Irvanizam ${ }^{6}$ \\ ${ }^{1}$ Department of Chemistry, Faculty of Mathematics and Natural Sciences, Universitas Syiah \\ Kuala, Kopelma Darussalam, Banda Aceh 23111, Indonesia \\ ${ }^{2}$ Department of Pharmacy, Faculty of Mathematics and Natural Sciences, Universitas Syiah \\ Kuala, Kopelma Darussalam, Banda Aceh 23111, Indonesia \\ ${ }^{3}$ Department of Chemistry, Faculty of Science and Technology, Universitas Islam Negeri Ar- \\ Raniry, Kopelma Darussalam, Banda Aceh 23111, Indonesia \\ ${ }^{4}$ Department of Chemical Engineering, Faculty of Engineering, Universitas Syiah Kuala, \\ Kopelma Darussalam, Banda Aceh 23111, Indonesia \\ ${ }^{5}$ Department of Statistics, Faculty of Mathematics and Natural Sciences, Universitas Syiah \\ Kuala, Kopelma Darussalam, Banda Aceh 23111, Indonesia \\ ${ }^{6}$ Department of Informatics, Faculty of Mathematics and Natural Sciences, Universitas Syiah \\ Kuala, Kopelma Darussalam, Banda Aceh 23111, Indonesia \\ ${ }^{\square}$ Corresponding Author: rinaldi.idroes@unsyiah.ac.id
}

\begin{abstract}
The dead time determination with the spreadsheet method has been conducted on the HPLC system with 2-alkanones homolog series, eluted with several composition ratios of acetonitrile/water solvent. The accuracy of the spreadsheet method is compared against the iteration method, according to the principle of (1) the smallest dead time; (2) the smallest standard deviation of the different dead time values given by the different solvent composition ratios; and (3) the highest linearity of the correlation between the natural logarithm of capacity factor $\ln \left(\mathrm{k}^{\prime}\right)$ versus carbon number $\mathrm{n}_{\mathrm{c}}$. The comparison results suggest that the spreadsheet method has equally good criteria with the iteration method. The use of acetonitrile/water solvent exhibits the improved accuracy of the dead time determination with smaller dead time values and standard deviation than the ones given by the methanol/water solvent.
\end{abstract}

Keywords: Liquid Chromatography, Alkanones, Dead Time, Solvent Composition, Mathematical Methods

RASĀYAN J. Chem., Vol. 14, No.2, 2021

\section{INTRODUCTION}

In chemical and pharmaceutical research, chromatography is very often used. ${ }^{1}$ The instrument plays an important role in separating compounds in extracts such as fatty acid ${ }^{2}$, alkaloids, ${ }^{3-5}$ organosulfur, ${ }^{6}$ organophosphate, ${ }^{7}$ essential oils, ${ }^{8}$ pyrethroid pesticides ${ }^{9}$ and others. However, chromatography cannot provide chemical information from separated compounds. The identification of these compounds is usually done by Nuclear Magnetic Resonance Spectroscopy ${ }^{10,11}$ or Mass-Spectrometry. ${ }^{12-14}$ This limitation is caused by the non-specificity of retention time as a parameter from chromatography analysis. The compound can have many retention times depending on instrument operating conditions such as temperature and column polarity. ${ }^{15}$ To overcome this limitation, several secondary parameters were developed including capacity factor ${ }^{16}$ and retention index ${ }^{17-21}$ which made it possible to obtain chemical information such as relative polarity ${ }^{22}$ and carbon numbers. ${ }^{23}$

The determination of secondary parameters requires dead time data. Dead time validates retention time to obtain adjusted retention time, the true interaction time of eluted compound in the chromatography column. 
RASĀYAN J. Chem.

Vol. 14 | No. 2 |1041-1048| April - June | 2021

The adjusted retention time represents chemical phenomena between the eluted compound and stationary phase that can be used to calculate the secondary parameter. So, the accuracy of dead time becomes important in obtaining the true chemical information of the secondary parameter.

Deadtime studies in liquid chromatography systems still leave many challenges up to these days. It is caused by the absence of standard regulation in generating the accuracy standard of dead time determination. In the gas chromatography system, the dead time is defined as the required time for the unretained substance to flow through a chromatography column. ${ }^{24}$ Meanwhile, in liquid chromatography, the unretained substance is not applicable. ${ }^{25}$ Even the solvent carrying the substance can be retained in the chromatography column.

To solve the problem, the dead time study in the liquid chromatography system is focused on the homologs series method. The retention data of homologs series that are determined in isocratic condition calculated with a specific algorithm to obtain the dead time value. Among developed algorithms for the liquid chromatography system are linearization, ${ }^{26}$ graphic, ${ }^{27}$ and non-linear. ${ }^{28}$ Some algorithms, which were initially developed for gas chromatography, have been also successfully applied to liquid chromatography, some of them are iteration, multiparametric, and statistic. ${ }^{29}$

Even though the ideal accuracy standard for dead time determination is still inapplicable on the liquid chromatography system, several approaches have been suggested to determine the best method for the application. At least, three approaches can be used, they are; (1) the lower the dead time value generated, ${ }^{30}$ (2) the more linear the correlation between the natural logarithm of capacity factor versus carbon number and (3) the smaller the standard deviation between the dead time generated by different solvent composition ratios, ${ }^{31}$ the more accurate the determination method of the dead time.

Several types of research related to the comparison of dead time determination methods have been conducted. Deadtime data determined from homolog series of n-alkane, alkylarylketone, 2-alkanone, and alkylbenzene, in some solvent compositions, suggest that, in determining the dead time, the iteration method gives higher accuracy than the linearization method. ${ }^{32}$ The most current work by Idroes et $\mathrm{al}^{33}$ reported the dead time of 2-alknanone homologs series eluted by methanol/water solvents. The determination results suggested that the spreadsheet method gives the dead time that is as good as the iteration method.

The difference of dead time values given by different ratios of solvent composition indicates the changed retention pattern of homologs series, which in the end, affects the dead time determination. By referring to the ideal dead time value, the solvent should give as minimum effect as possible. In this research, several acetonitrile/water solvent composition ratios were used to elute the 2-alkanone homologs series. The given retention data were then used for dead time determination with spreadsheet and iteration methods. The accuracy is evaluated by comparing the received dead time value, linearity, and the effect of solvent composition ratios.

\section{Material}

\section{EXPERIMENTAL}

Homologs series used included 2-alkanone (2-butanone up to 2-dodecanone) purchased from Riedel de Haehn. Eluent used were HPLC grade acetonitrile purchased from Roth, HPLC grade water and HPLC grade tetrahydrofuran purchased from Merck.

\section{Instrument}

The instruments used are RP-HPLC. Lichrospher column 100 RP-18 (Merck) with a particle diameter of 5 $\mu \mathrm{m}$, Bischoff pump model 2200 (serial 903), RI-detector model ERC-7510, and Recorder HP-3394 Hewlett-Packard.

\section{Procedure}

Five solvent composition ratios of acetonitrile: water $(\mathrm{v} / \mathrm{v})$ were made with the following variations: 80/20; 70/30; 60/40; 50/50; and 40/60. RP-HPLC equipment was set by running it until the constant was reached. The water jacket was set at $30{ }^{\circ} \mathrm{C}$. The flow rate of the solvent was set at $1 \mathrm{~mL} / \mathrm{min}$. Nine replicates of 2alkanone homologs series (2-Butanone until 2-Dodecanone) were prepared. One $\mathrm{mL}$ of each replicate was diluted into $10 \mathrm{~mL}$ tetrahydrofuran. The solution was then eluted with the respective solvent composition with a ratio between solution and solvent was 1:100. 
RASĀYAN J. Chem.

Vol. 14 | No. 2 |1041-1048| April - June | 2021

The data of retention times were tabulated with Excel. The data were used to determine the dead time by spreadsheet $^{34}$ and iteration ${ }^{35}$ algorithm. The obtained dead time of the two methods was compared to generate the lowest dead time value and t-test result. The effect of the solvent composition ratio was evaluated by calculating the standard deviation and \% error from the 5 dead times of the respective solvent compositions. The linearity was calculated by generating linear plots between the natural logarithm of capacity factor versus carbon number.

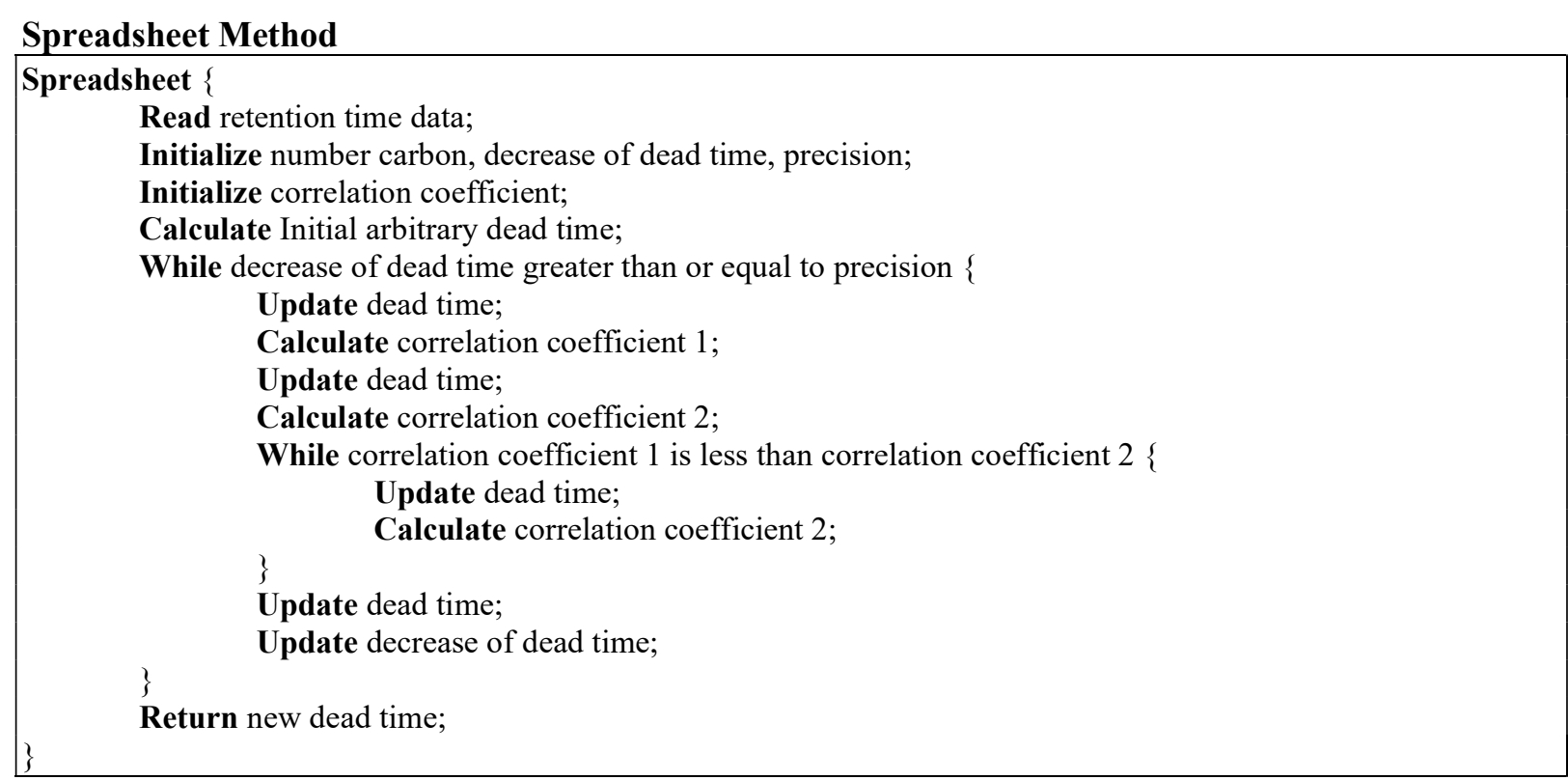

Fig.-1: The Pseudocode of the Spreadsheet Method

The spreadsheet method was developed by Braithwaite, et al based on changes in the correlation coefficient values. Figure-1 shown the pseudocode of the spreadsheet method. The method starts with initializing the number of carbons, a decrease of dead time, precision values. The main process is repetition which updates the value of the correlation coefficient until it reaches precision. The final result of the dead time was carried out based on the optimal correlation coefficient. The complete algorithm of the spreadsheet method (spreadsheet macro) presented in the literature of Braithwaite, et $\mathrm{a}^{34}$ and the flowchart of the method also can be seen in literature Idroes, et al. ${ }^{24}$

Iteration Method

Iteration

Read retention time data;

Initialize number carbon, dead time, a decrease of dead time, precision, SUM, SAM;

While decrease of dead time greater than precision \{ Do \{

Calculate adjusted retention time;

Calculate least square adjustment;

Calculate approximate retention index;

Calculate sum of differential retention index;

Update SUM, SAM, dead time;

\}

While (Sum of differential retention index is greater than SUM)

IF (Sum of differential retention index is greater than or equals to SAM)

\{

Update dead time, SUM;

\}

Else \{ 
RASĀYAN J. Chem.

Vol. 14 | No. 2 |1041-1048| April - June | 2021

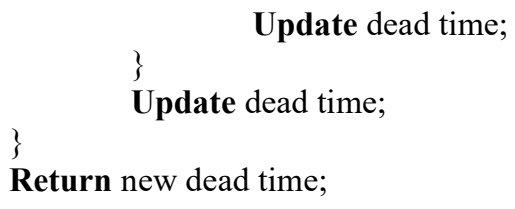

Fig.-2: The Pseudocode of the Iteration Method

The iteration method was developed by Guardino, et al based on the square of the deviations of the theoretical retention index of n-alkanes that are minimized concerning the retention index calculated ${ }^{35}$. In the main looping, the calculation of the least square adjustment, approximate retention index, the sum of differential retention index is carried out to produce an optimal dead time value. The iteration method was implemented in visual basic by Furr, et al. ${ }^{36}$ The same method was also implemented by Idroes et al in the newer programming language ANSII C. ${ }^{24}$ The pseudocode of the iteration method can be seen in Fig.-2 and the complete flowchart of the method presented in the literature Guardino, et al. ${ }^{35}$

\section{RESULTS AND DISCUSSION}

In liquid chromatography, the determination method resulting in the best dead time is conducted by three statistical approaches, they are the methods with: (1) the smallest dead time; (2) the smallest standard deviation of the different dead time values given by the different solvent composition ratios; and (3) the highest linearity of the correlation between the natural logarithm of capacity factor $\ln \left(\mathrm{k}^{\prime}\right)$ versus carbon number $\mathrm{n}_{\mathrm{c}}$.

In evaluating the ability of a method, a method comparison is required, which includes the previous methods that have been scientifically proven to have a superiority compared to other methods. In several reported studies on the method comparison for dead time determination, the iteration method is suggested to be the most accurate and relatively quick among other methods, either for gaseous chromatography system ${ }^{37,38}$ or liquid chromatography system. ${ }^{39}$

Table-1: The Dead time of 2-alkanones Homologous Series eluted in Some Acetonitrile/Water Eluent Composition

\begin{tabular}{|c|c|c|c|c|c|c|c|c|}
\hline \multirow{2}{*}{ Methods } & \multicolumn{5}{|c|}{ Eluent Composition (Acetonitrile/Water) } & \multirow{2}{*}{ Mean } & \multirow{2}{*}{$\mathrm{SD}$} & \multirow{2}{*}{$\begin{array}{c}\text { Error } \\
(\%)\end{array}$} \\
\hline & $80 / 20$ & $70 / 30$ & $60 / 40$ & $50 / 50$ & $40 / 60$ & & & \\
\hline Iteration & 1.126 & 1.150 & 1.125 & 1.112 & 1.173 & 1.137 & 0.024 & 2.426 \\
\hline Spreadsheet & 1.127 & 1.150 & 1.126 & 1.112 & 1.170 & 1.137 & 0.023 & 2.293 \\
\hline
\end{tabular}

The determination results suggest that the dead time of both methods, spreadsheet and iteration, are relatively equal in all composition ratios of acetonitrile/water eluent (Table-1). It is confirmed by the $t$-test (Table-2). The differences of the average dead time obtained from the spreadsheet method versus iteration method, respectively, are not significant, indicated by the same alphabet $(a)^{40}$ label for the test results of the respective ratio compositions. The data suggest that the spreadsheet method is equally good with the iteration method in giving the dead times that are as small as possible.

Table-2: The Result of the $t$-test for the Differences of the Average Dead time Obtained from the Spreadsheet Method Versus the Iteration Method

\begin{tabular}{c|c|c|c|c|c}
\hline \multirow{2}{*}{ Methods } & \multicolumn{5}{|c}{ Eluent Composition (Acetonitrile/Water) } \\
\cline { 2 - 6 } & $80 / 20$ & $70 / 30$ & $60 / 40$ & $50 / 50$ & $40 / 60$ \\
\hline Spreadsheet & $0.173^{\mathrm{a}}$ & $0.616^{\mathrm{a}}$ & $0.492^{\mathrm{a}}$ & $0.786^{\mathrm{a}}$ & $1.660^{\mathrm{a}}$ \\
\hline Iteration & $0.171^{\mathrm{a}}$ & $0.616^{\mathrm{a}}$ & $0.490^{\mathrm{a}}$ & $0.786^{\mathrm{a}}$ & $1.660^{\mathrm{a}}$ \\
\hline
\end{tabular}

Information: The average values with the same alphabet are not significantly different.

The study of dead time determination in the gas chromatography system indicates that the polarity of a column mobile phase does not significantly affect the obtained dead time, either from the marker or the homologs series method. Helium gas used as the mobile phase is also confirmed to have no interaction, either with the stationary phase or the eluted components. ${ }^{38}$ It indicates that inert components used in the 
RASĀYAN J. Chem.

Vol. 14 | No. 2 |1041-1048| April - June | 2021

marker method or the algorithms used in the homologs series method in the gas chromatography system can meet the principle requirement of ideally unretained dead time.

In contrary to the mobile phase in liquid chromatography, solvent mixtures are used as the components, such as the mixture of water and methanol, acetonitrile, or tetrahydrofuran, which contributes to a certain degree of polarity. Besides, the composition ratio of the solvent mixture can be varied to adjust with the eluted component. It gives a result to an ideal determination of the dead time, in line with the unretained principle, that is impossible to be conducted on liquid chromatography. The best approach to evaluate the ability of a method is by evaluating the minimum effect of the solvent composition ratio against the determination of the dead time. The less it affects the dead time, the better the determination method is ${ }^{31}$. The results of the dead time determination of both spreadsheet methods indicate that each solvent composition ratio gives the different dead times. It suggests that different composition ratios of acetonitrile/water solvent affect the dead time determination. The extent of the effect can be observed through the relative standard deviation, which is $2.426 \%$ and $2.293 \%$ for iteration and spreadsheet methods, respectively (Table-1). The relatively equivalent values of the relative standard deviation indicate that the spreadsheet method meets the criteria as well as the iteration method.

Table-3: Natural Logarithm of Capacity Factor from 2-alkanone Homologous Series in each Eluent Composition

\begin{tabular}{|c|c|c|c|c|c|c|c|c|c|c|}
\hline \multirow{3}{*}{$\mathrm{n}_{\mathrm{c}}$} & \multicolumn{10}{|c|}{$\ln \left(\mathrm{k}^{\prime}\right)$} \\
\hline & \multicolumn{5}{|c|}{ Spreadsheet Dead time } & \multicolumn{5}{|c|}{ Iteration Dead time } \\
\hline & $80 / 20$ & $70 / 30$ & $60 / 40$ & $50 / 50$ & $40 / 60$ & $80 / 20$ & $70 / 30$ & $60 / 40$ & $50 / 50$ & $40 / 60$ \\
\hline 4 & & & -0.927 & -0.604 & & & & -0.931 & -0.604 & \\
\hline 5 & & -0.853 & -0.453 & -0.040 & 0.318 & & -0.853 & -0.456 & -0.040 & 0.318 \\
\hline 6 & -0.887 & -0.414 & 0.035 & 0.508 & 0.978 & -0.890 & -0.414 & 0.033 & 0.508 & 0.978 \\
\hline 7 & -0.543 & -0.009 & 0.495 & 1.063 & 1.657 & -0.546 & -0.009 & 0.493 & 1.063 & 1.657 \\
\hline 8 & -0.176 & 0.403 & 0.959 & 1.616 & 2.334 & -0.178 & 0.403 & 0.958 & 1.616 & 2.334 \\
\hline 9 & 0.177 & 0.820 & 1.431 & 2.173 & 3.014 & 0.175 & 0.820 & 1.430 & 2.173 & 3.014 \\
\hline 10 & 0.525 & 1.236 & 1.902 & & & 0.524 & 1.236 & 1.901 & & \\
\hline 11 & 0.880 & 1.659 & & & & 0.878 & 1.659 & & & \\
\hline 12 & 1.238 & 2.083 & & & & 1.237 & 2.083 & & & \\
\hline
\end{tabular}

Apart from the solvent composition ratio, the type of solvent also gives an effect on the determination of dead-time values. Idroes et $\mathrm{al}^{33}$ reported the dead times determined with the calculation methods, the type of homologs series, and the solvent composition ratios that are the same with this research, but with methanol/water solvent, have relatively higher relative standard deviation. The relative standard deviations obtained with the methanol/water solvent were $3.529 \%$ and 3.247 for spreadsheet and iteration methods, respectively.

The type of solvent also gives an effect on the dead time values. Deadtime values obtained from the spreadsheet method with methanol/water solvent for all composition ratios are within the range of 1.1361.214 minutes or the average of $1.181 \pm 0.033$ minutes. This number is far greater compared with the dead time values obtained from acetonitrile/water solvent, which are within the range of 1.112-1.150 minutes or within the average of $1.137 \pm 0.023$ minutes. Based on the dead time values and the relative standard deviation of the dead time, acetonitrile/water solvent gives a better determination of the dead time compared to methanol/water solvent.

The essence of dead time values is their role as the main data in determining secondary retention parameters such as adjusted retention time, capacity factor, retention index, and others ${ }^{41,42}$. Secondary retention parameters represent the physical-chemical and thermodynamic information of the interaction phenomena between the separated compound and the stationary phase. In a compound elusion process, in the chromatography column, retention time does not represent the real-time used by the compound to interact with the stationary phase, but the combination of the total time with interaction (a component in the mobile phase/static condition) and the total time with no interaction (a component in stationary phase/dynamic condition).

The total time of the component to interact with the stationary phase is stated as adjusted retention time, meanwhile, total time with no interaction is stated as dead time. In other words, dead time corrects retention time to obtain the adjusted retention time (interaction time/real retained). The ratio of total time with 
RASĀYAN J. Chem.

interaction (adjusted retention time) and the total time with no interaction (dead time) is stated as the capacity factor. In the elution of homologs series with the chemical pattern of the increasing carbon number, there is a possibility of a systematic correlation between carbon number and the two secondary parameters (adjusted retention time or factor capacity).

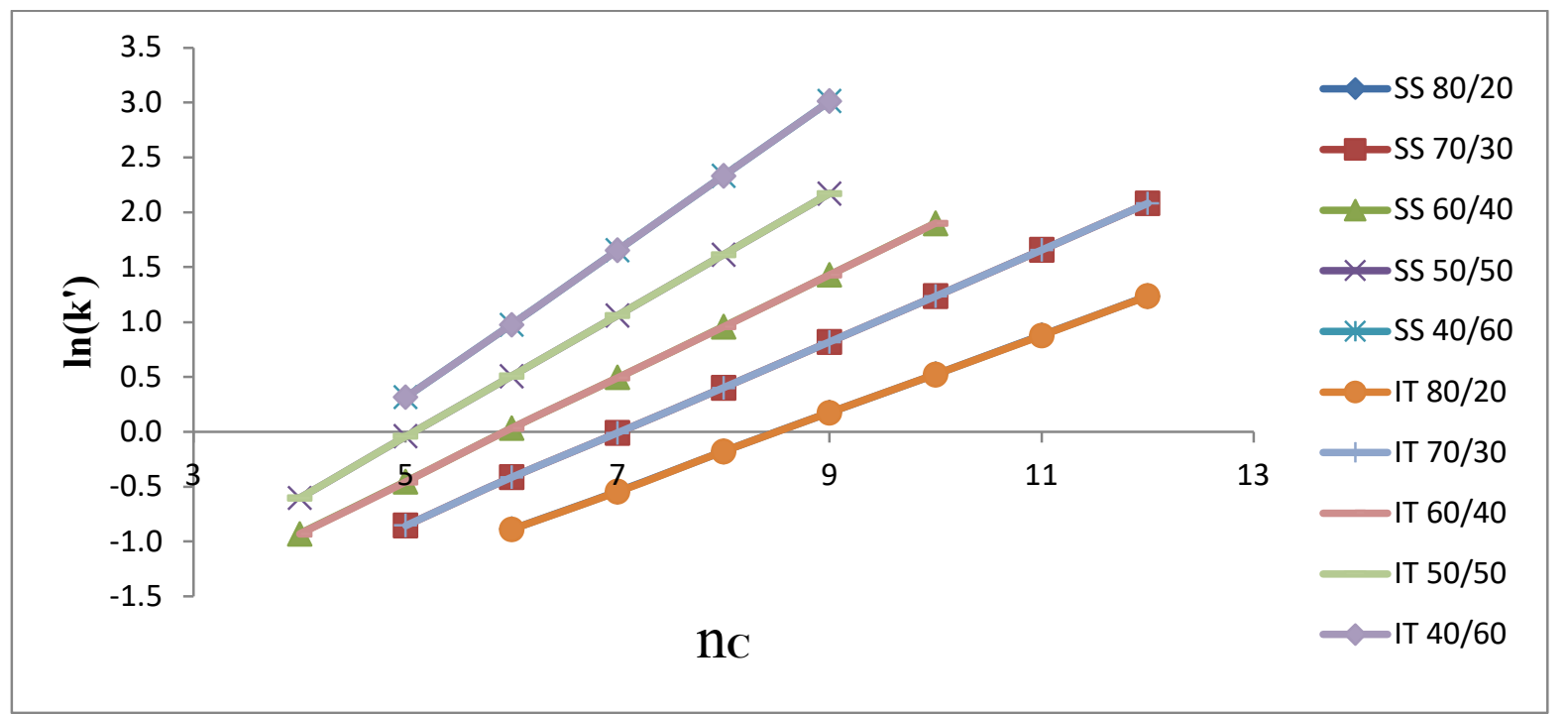

Fig.-3: Overlay of the Plot of the Natural Logarithm of Capacity Factor Versus Carbon Number; SS (Spreadsheet) and IT (Iteration)

Table-4: Linear Regression Parameters between the Natural Logarithm of Capacity Factor and Carbon Number

\begin{tabular}{|c|c|c|c|c|c|c|}
\hline \multirow{2}{*}{ Methods } & \multirow{2}{*}{$\begin{array}{l}\text { Regression } \\
\text { Parameters }\end{array}$} & \multicolumn{4}{|c|}{ Eluent Composition } & \multirow[b]{2}{*}{$40 / 60$} \\
\hline & & $80 / 20$ & $70 / 30$ & $60 / 40$ & $50 / 50$ & \\
\hline \multirow{6}{*}{ Spreadsheet } & Slope & 0.35466 & 0.41747 & 0.47104 & 0.55451 & 0.67481 \\
\hline & Sdv. Slope & 0.00094 & 0.00119 & 0.00147 & 0.00080 & 0.00210 \\
\hline & Intercept & -3.02035 & -2.93301 & -2.80750 & -2.81840 & -3.06353 \\
\hline & Sdv. Intercept & 0.00864 & 0.01050 & 0.01071 & 0.00538 & 0.01501 \\
\hline & Sdv. Regression & 0.00496 & 0.00773 & 0.00779 & 0.00335 & 0.00665 \\
\hline & $\begin{array}{c}\text { Coefficient } \\
\text { Determination }\end{array}$ & 0.99997 & 0.99995 & 0.99995 & 0.99999 & 0.99997 \\
\hline \multirow{6}{*}{ Iteration } & $\begin{array}{c}\text { Coefficient } \\
\text { Determination }\end{array}$ & 0.99997 & 0.99995 & 0.99995 & 0.99999 & 0.99997 \\
\hline & Sdv. Regression & 0.00496 & 0.00773 & 0.00757 & 0.00335 & 0.00665 \\
\hline & Slope & 0.35435 & 0.41747 & 0.47071 & 0.55451 & 0.67481 \\
\hline & Sdv. Slope & 0.00094 & 0.00119 & 0.00143 & 0.00080 & 0.00210 \\
\hline & Intercept & -3.01576 & -2.93301 & -2.80348 & -2.81840 & -3.06353 \\
\hline & Sdv. Intercept & 0.00864 & 0.01050 & 0.01042 & 0.00538 & 0.01501 \\
\hline
\end{tabular}

In an ideal condition, there is a linear correlation between natural logarithms of the capacity factor and the carbon number. The linearity of the correlation is determined by the determination accuracy of the factor capacity, in this case, is the accuracy of the dead time determination. The more accurate the dead time determination, the more linear the correlation.

Natural logarithms of the capacity factor of homologs series 2-alkanone eluted with a composition variation of acetonitrile/water solvent system had been calculated from the dead time obtained with spreadsheet and iteration methods (Table-3). The data were then plotted on the linear curve against the respective carbon number (Fig.-3). Linear overlays exhibit the comparison of the two lines from spreadsheet and iteration methods, at the same solvent composition, which is precisely equal. The linearity of each line is observed by the obtained determination coefficient (Table-4). Both methods give precisely equal coefficient determination with the equally high linearity, reaching four decimals, which is 0.9999 . The best correlation 
RASĀYAN J. Chem.

Vol. 14 | No. 2 |1041-1048| April - June | 2021

coefficient is given by the solvent composition ratio of 50/50 with the coefficient determination of 0.99999 . These results suggest that the spreadsheet method has the criteria that are equally good with the iteration method in generating the linearity of natural logarithm plots of capacity factor vs. carbon number.

\section{CONCLUSION}

The determination of dead time with the spreadsheet method had been conducted in the HPLC system using homologues series 2-alkanone eluted with several comparisons of acetonitrile/water solvent compositions. Based on the principle: (1) the smallest dead time; (2) the smallest standard deviation of the different dead time values given by the different solvent composition ratios; and (3) the highest linearity of the correlation between the natural logarithm of capacity factor $\ln \left(\mathrm{k}^{\prime}\right)$ versus carbon number $\mathrm{n}_{\mathrm{c}}$, the spreadsheet method is equally good the iteration method. The type of solvent also gives an effect on the accuracy of the dead time determination. The use of acetonitrile/water solvent gives more accurate dead times with the dead time value and the standard deviation smaller than methanol/water solvent.

\section{REFERENCES}

1. R. Raj, K. S. Chandrashekar, R. Biswas, A. Pai, V. Pai, Rasayan Journal of Chemistry, 14(1), 221(2021), DOI:10.31788/RJC.2021.1415991

2. N. Earlia, R. Rahmad, M. Amin, C. Prakoeswa, K. Khairan, R. Idroes, Sains Malaysiana, 48, 1019(2019), DOI: 10.17576/jsm-2019-4805-10

3. Y. Gao, S. Hu, M. Zhang, L. Li, Y. Lin, Journal of Pharmaceutical and Biomedical Analysis, 92, 6(2014), DOI: 10.1016/j.jpba.2013.12.037

4. S. G. Tumilaar, F. Fatimawali, N. J. Niode, Y. Effendi, R. Idroes, A. A. Adam, A. Rakib, T. Bin Emran, T. E. Tallei, Journal of Applied Pharmaceutical Science, 11, 101(2021),DOI:10.7324/JAPS.2021.110112

5. C. Nuraskin, Marlina, R. Idroes, C. Soraya, Djufri, Rasayan Journal of Chemistry, 13(1), 18(2020), DOI: $10.31788 /$ RJC.2020.1315434

6. E. C. Estevam, S. Griffin, M. J. Nasim, D. Zieliński, J. Aszyk, M. Osowicka, N. Dawidowska, R. Idroes, A. Bartoszek, C. Jacob, Natural Product Communications, 10, 1934578X1501001(2015), DOI: $10.1177 / 1934578 X 1501001025$

7. K. Khoiriah, S. Safni, S. Syukri, J. Gunlazuardi, Rasayan Journal of Chemistry, 13(3), 1919(2020), DOI: $10.31788 /$ RJC.2020.1335743

8. E. Sufriadi, H. Meilina, A. A. Munawar, S. Muhammad, R. Idroes, IOP Conference Series: Earth and Environmental Science, 12032, DOI:10.1088/1755-1315/667/1/012032

9. M. Yusuf, R. Idroes, Saiful, Lelifajri, T. K. Bakri, M. Satria, H. Nufus, I. Yuswandi, Z. Helwani, Muslem, Marlina, IOP Conference Series: Earth and Environmental Science, 12039, DOI: $10.1088 / 1755-1315 / 667 / 1 / 012039$

10. Q. Zhou, Y.-H. Fu, X. Li, G.-Y. Chen, S.-Y. Wu, X.-P. Song, Y.-P. Liu, C.-R. Han, Phytochemistry Letters, 11, 296(2015), DOI:10.1016/j.phytol.2015.01.017

11. H. Hayun, I. Gavrila, S. Silviana, A. E. K. Siahaan, R. F. Vonna, M. I. Latifah, Rasayan Journal of Chemistry, 13(1), 131(2020), DOI:10.31788/RJC.2020.1315300

12. S. U. T. Pratiwi, E. L. Lagendijk, S. de Weert, R. Idroes, T. Hertiani, C. Van den Hondel, International Journal of Applied Research in Natural Products, 8, 1(2015)

13. N. Earlia, Muslem, R. Suhendra, M. Amin, C. R. S. Prakoeswa, Khairan, R. Idroes, The Scientific World Journal, 2019, 1(2019), DOI:10.1155/2019/8605743

14. H. P. C. A. Cane, N. Saidi, M. Mustanir, D. Darusman, R. Idroes, M. Musman, Rasayan Journal of Chemistry, 13(4), 2215(2020), DOI:10.31788/RJC.2020.1345818

15. R. Idroes, Muslem, Mahmudi, Saiful, M. Paristiowati, G. M. Idroes, R. Suhendra, A. Maulana, T. R. Noviandy, Irvanizam, IOP Conference Series: Materials Science and Engineering, 12068, DOI: $10.1088 / 1757-899 \mathrm{X} / 1087 / 1 / 012068$

16. J. H. Knox, R. Kaliszan, Journal of Chromatography A, 349, 211(1985), DOI:10.1016/S00219673(01)83779-1

17. E. Kováts, Helvetica Chimica Acta, 41, 1915(1958), DOI:10.1002/hlca.19580410703 
RASĀYAN J. Chem.

Vol. 14 | No. 2 |1041-1048| April - June | 2021

18. R. Idroes, A. F. Japnur, R. Suhendra, A. Rusyana, IOP Conference Series: Materials Science and Engineering, 523, 012007(2019), DOI:10.1088/1757-899X/523/1/012007

19. R. Idroes, R. Suhendra, Muslem, Mahmudi, G. M. Idroes, Kromatografi Gas : Waktu Mati dan Indeks Retensi Kovats, Syiah Kuala University Press, Banda Aceh, Indonesia

20. A. Maulana, T. R. Noviandy, R. Idroes, N. R. Sasmita, R. Suhendra, I. Irvanizam, 2020 International Conference on Electrical Engineering and Informatics (ICELTICs), 1-5, DOI: 10.1109/ICELTICs50595.2020.9315391

21. T. R. Noviandy, A. Maulana, N. R. Sasmita, R. Suhendra, Muslem, G. M. Idroes, M. Paristiowati, Z. Helwani, E. Yandri, S. Rahimah, Muhammad, Irvanizam, R. Idroes, IOP Conference Series: Materials Science and Engineering, 12051, DOI:10.1088/1757-899X/1087/1/012051

22. I. Husna, A. Rusyana, Muslem, G. M. Idroes, R. Suhendraand, R. Idroes, IOP Conference Series: Materials Science and Engineering, 12064, DOI:10.1088/1757-899X/796/1/012064

23. R. Idroes, T. R. Noviandy, A. Maulana, R. Suhendra, N. R. Sasmita, M. Muslem, G. M. Idroes, I. Irvanizam, International Review on Modelling and Simulations (IREMOS), 12, 373(2019), DOI: 10.15866/iremos.v12i6.18353

24. R. Idroes, Muslem, Mahmudi, Saiful, G. M. Idroes, R. Suhendra, Irvanizam, Heliyon, 6, e03302(2020), DOI: 10.1016/j.heliyon.2020.e03302

25. F. Gritti, Y. Kazakevich, G. Guiochon, Journal of Chromatography A, 1161, 157(2007), DOI:10.1016/j.chroma.2007.05.102

26. G. E. Berendsen, P. J. Schoenmakers, L. de Galan, G. Vigh, Z. Varga-puchony, J. Inczédy, Journal of Liquid Chromatography, 3, 1669(1980), DOI:10.1080/01483918008064759

27. R. J. Laub, S. J. Madden, Journal of Liquid Chromatography, 8, 173(1985), DOI: $10.1080 / 01483918508067070$

28. H. Wätzig, S. Ebel, Chromatographia, 31, 544(1991), DOI:10.1007/BF02279473

29. L. Didaoui, A. Touabet, A. Y. Badjah Hadj Ahmed, B. Y. Meklati, W. Engewald, HRC Journal of High Resolution Chromatography, 22, 559(1999), DOI:10.1002/(SICI)15214168(19991001)22:10<559::AID-JHRC559>3.0.CO;2-R

30. C. W. Ehrensberger, Beiträge zur Reproduzierbarkeit und zur Vorhersage von Retentionsdaten in der $H P L C$, Verlag nicht ermittelbar

31. B. A. Bidlingmeyer, F. V. Warren, A. Weston, P. M. Froehlich, D. Way, Journal of chromatographic science, 29, 275(1991), DOI:10.1093/chromsci/29.7.275

32. R. Idroes, Malaysian Journal of Analytical Sciences, 9, 224(2005)

33. R. Idroes, Muslem, Saiful, Mahmudi, G. M. Idroes, R. Suhendra, Irvanizam, Zamzami, M. Paristiowati, IOP Conference Series: Earth and Environmental Science, DOI:10.1088/1755-1315/364/1/012033

34. A. Braithwaite, M. Cooper, Chromatographia, 37, 86(1993), DOI:10.1007/BF02272194

35. X. Guardino, J. Albaiges, G. Firpo, R. Rodriguez-Vinals, M. Gassiot, Journal of Chromatography A, 118, 13(1976), DOI: 10.1016/S0021-9673(00)81026-2

36. H. C. Furr, Journal of Chromatographic Science, 27, (1989), DOI:10.1093/chromsci/27.5.216

37. R. J. Smith, J. K. Haken, M. S. Wainwright, Journal of Chromatography A, 334, 95(1985), DOI: 10.1016/S0021-9673(00)80268-X

38. J. E. Quintanilla-López, R. Lebrón-Aguilar, J. García-Domínguez, Journal of Chromatography A, 767, 127(1997), DOI:10.1016/S0021-9673(96)01033-3

39. R. Idroes, Indonesian J. Pharmacy, 20, 133(2009)

40. R. Idroes, I. Husna, Muslem, Mahmudi, A. Rusyana, Z. Helwani, G. M. Idroes, R. Suhendra, E. Yandri, S. Rahimah, N. R. Sasmita, IOP Conference Series: Earth and Environmental Science, DOI: $10.1088 / 1755-1315 / 364 / 1 / 012020$

41. R. Idroes, Air, Majalah Farmasi Indonesia (Indonesian Journal of Pharmacy), 20, 77(2009)

42. R. Idroes, Indonesian Journal of Chemistry, 10, 58(2010), DOI:10.22146/ijc.21480

[RJC-6024/2020] 